Check for updates

London, UK

Cite this as: BMJ 2020;370:m3748 http://dx.doi.org/10.1136/bmj.m3748 Published: 25 September 2020

\title{
Covid-19: Learn from other countries about easing lockdown, researchers urge
}

\section{Shaun Griffin}

The authors of a new review of international experiences of easing lockdown during the covid-19 pandemic are urging governments to consider a "zero-covid-19" strategy to eliminate domestic transmission, among other measures. ${ }^{1}$

For their analysis in the Lancet the authors reviewed strategies for easing restrictions in nine high income countries: Germany, Hong Kong, Japan, New Zealand, Norway, Singapore, South Korea, Spain, and the UK.

They proposed five factors to consider when developing strategies to ease restrictions: knowledge of infection levels, community engagement, public health capacity, health system capacity, and border control measures.

At the same time, they expressed concern about the absence of clear and consistent strategic approaches and the significant variation between countries in public health responses so far. They noted, for example that from the start of the outbreak many Asian countries instituted extensive test, trace, and isolation of all covid-19 cases, strengthened by innovative surveillance technology. Except for Germany, these processes have been delayed considerably in most of Europe.

They also noted that while confirmed cases have mostly been isolated at home in Europe, they have mostly been isolated in institutions in the Asian countries studied. There was also greater adoption of face coverings in Asia, at least initially.

Recent experience of severe acute respiratory syndrome and Middle East respiratory syndrome also meant that many Asian countries already had robust infrastructures. Meanwhile, in Europe, public health systems in Spain and the UK struggled with the consequences of a decade of austerity, they said.

Helena Legido-Quigley of the National University of Singapore and London School of Hygiene and Tropical Medicine, lead author on the paper, said, "There is increasing realisation that easing of lockdown is not about returning to a pre-pandemic normal, and governments have to find strategies that will prevent rapid growth of infections in ways that are sustainable and acceptable to the public over many months."

Before easing restrictions, the authors urged governments to adopt five measures. Firstly, a clear plan with transparent decision making, stating the levels of restriction easing, containment measures, and criteria for moving between levels.

Secondly, robust systems to monitor infection. In the case of the $R$ value, they caution the need for real time, high quality data that is interpreted epidemiologically, as in Hong Kong where real time R estimates are used.

Thirdly, they said that for communities to reopen safely, control measures to reduce transmission will be needed for some time. They cite New Zealand's social bubbles as a successful example that allows social interaction while reducing transmission. The authors also highlight the need for public engagement and involvement.

Fourthly, each country must have an effective test, trace, and isolate system. They noted that while the UK and Spain have struggled with this, South Korea's approach has encouraged proactive testing and case finding. They also called for sustained investment in health systems and public health.

Finally, the authors believe there is a strong argument for adopting a "zero-covid-19" strategy that aims to eliminate domestic transmission, particularly with emerging evidence of long covid. ${ }^{23}$

Legido-Quigley said, "We are not advising that the exact same measures should be replicated in different countries, but it is not too late for governments to consider novel policy solutions developed by other countries and adapt them to fit their own context."

Co-author Yik-Ying Teo of the National University of Singapore added "We were concerned about the large divergence in government preparedness. There is a need to understand the contextual differences that have led to such contrasting results, and to identify common principles that governments can follow to protect their people and the economy."

Han E, Tan MMJ, Turk E, et al. Lessons learnt from easing covid-19 restrictions: an analysis of countries and regions in Asia Pacific and Europe Lancet 2020;(September). doi: 10.1016/S0140-6736(20)32007-9.

2 Torjesen I. Covid-19: Should the UK be aiming for elimination?BMJ 2020;370:m3071. doi: 10.1136/bmj.m3071 pmid: 32747404

3 Mahase E. Covid-19: What do we know about "long covid"?BMJ 2020;370:m2815. doi: 10.1136/bmi.m2815 pmid: 32665317 